\title{
Spatiotemporal Changes in the Urban Heat Island Intensity of Distinct Local Climate Zones: Case Study of Zhongshan District, Dalian, China
}

\author{
Jun Han, ${ }^{1}$ Jiatong Liu, ${ }^{1}$ Liang Liu $\left(D,{ }^{1}\right.$ and Yuanzhi Ye $\mathbb{D}^{2}$ \\ ${ }^{1}$ School of Geography, Liaoning Normal University, Dalian 116029, China \\ ${ }^{2}$ Zhejiang Academy of Surveying and Mapping, No. 2 Dixin Road, Wuchang Street, Yuhang District, \\ Hangzhou City 310023, China
}

Correspondence should be addressed to Liang Liu; liuliangdm@126.com and Yuanzhi Ye; xiaozhiyyz@hotmail.com

Received 13 August 2020; Revised 8 September 2020; Accepted 14 September 2020; Published 24 October 2020

Academic Editor: Jun Yang

Copyright $(2020$ Jun Han et al. This is an open access article distributed under the Creative Commons Attribution License, which permits unrestricted use, distribution, and reproduction in any medium, provided the original work is properly cited.

\begin{abstract}
Intensified due to rapid urbanization and global warming-induced high temperature extremes, the urban heat island effect has become a major environmental concern for urban residents. Scientific methods used to calculate the urban heat island intensity (UHII) and its alleviation have become urgent requirements for urban development. This study is carried out in Zhongshan District, Dalian City, which has a total area of $43.85 \mathrm{~km}^{2}$ and a $27.5 \mathrm{~km}$-long coastline. The mono-window algorithm was used to retrieve the land surface temperatures (LSTs), employing Landsat remote sensing images, meteorological data, and building data from 2003, 2008, 2013, and 2019. In addition, the district was divided into local climate zones (LCZs) based on the estimated intensities and spatiotemporal variations of the heat island effect. The results show that, from 2003 to 2019, LCZs A and D shrank by $3.225 \mathrm{~km}^{2}$ and $0.395 \mathrm{~km}^{2}$, respectively, whereas LCZs B, C, and $1-6$ expanded by $0.932 \mathrm{~km}^{2}, 0.632 \mathrm{~km}^{2}$, and $2.056 \mathrm{~km}^{2}$, respectively. During this period, the maximum and minimum LSTs in Zhongshan increased by $1.365^{\circ} \mathrm{C}$ and $1.104^{\circ} \mathrm{C}$, respectively. The LST and UHII levels of all LCZs peaked in 2019 . The average LSTs of LCZs A-C increased by $1.610^{\circ} \mathrm{C}, 0.880^{\circ} \mathrm{C}$, and $3.830^{\circ} \mathrm{C}$, respectively, and those of LCZs $1-6$ increased by $2^{\circ} \mathrm{C}-4^{\circ} \mathrm{C}$. The UHIIs of LCZs A, C, and D increased by $0.730,2.950$, and 0.344 , respectively, and those of LCZs 1-6 increased from 1.370-2.977 to 3.744-5.379. Overall, the regions with high LSTs are spatiotemporally correlated with high building densities. In this study, the land cover was then classified into four types (LCZs A-D) using visual interpretation and object-oriented classification, including forested land, low vegetation, bare ground, and water. Besides, the buildings were categorized as LCZs 1-6, which, respectively, represented low-density low-rises buildings, low-density high-rises buildings, low-density super high-rises buildings, high-density low-rises buildings, high-density high-rises buildings, and high-density super high-rises buildings.
\end{abstract}

\section{Introduction}

The urban population of China has grown significantly since the Chinese Economic Reform, with the permanent population urbanization rate of China reaching $60.60 \%$ in 2019 [1]. Although the rapid urbanization of China has promoted economic growth, it has also led to negative environmental consequences. According to the Fifth Assessment Report of the IPCC [1], the global average land surface temperature (LST) increased by $0.85^{\circ} \mathrm{C}$ from 1880 to 2012 , with global warming [2] as the defining climatic trait of this period [3,4].
In an effort to improve the quality of urban residential environments [5, 6], researchers worldwide have studied the drivers of changes in LST $[7,8]$ from a variety of perspectives, including social and cultural aspects [9-12]. According to these studies, large increases in construction land areas [13] have altered native landforms [14] and created numerous artificial heat sources $[15,16]$ that have degraded the quality of urban environments and significantly exacerbated the heat island effect. Howard was the first to propose and define these significantly elevated LSTs found in urban areas (as compared to the surrounding rural 
areas) as the urban heat island (UHI) effect. The difference between urban and rural LSTs is defined as the urban heat island intensity (UHII), which is an important metric for identifying UHIs [17]. In recent years, UHII levels have increased due to the combined actions of global warming and extreme heat waves. In addition to reducing the comfort of urban living [18], this phenomenon also poses a significant threat to the health of urban residents $[19,20]$.

At present, two methods are commonly used to measure the LST. The first is based on on-site observations of air temperatures at ground monitoring stations, and the second uses the inversion of thermal-infrared (TIR) remote sensing data to retrieve the LST product. Compared to the conventional observation-based method, which is limited by the number of weather monitoring stations and the nonuniformity of their distribution [21], TIR remote sensing is more time-effective [22] and robust against topographic effects [23, 24]. Therefore, TIR remote sensing is an effective tool for studying the spatial distribution of the UHI effect [25]. Urban climate researchers worldwide have used TIR remote sensing to study the relationship between the UHI effect and land-use types [26, 27] or blue-and-green spaces [28] and to establish metrics for assessing the UHII $[29,30]$. Although the UHI effect has been extensively studied, a standardized definition of UHII has yet to be agreed upon by the scientific community [17]. To this end, Auer [31] proposed a zonal approach to urban climatology, which was built upon by Stewart and Oke [32] to suggest urban climate zones (UCZs), where urban and rural landscapes are incorporated into the analysis to enable the description of temperature differences between different landforms. With this background, Mills and Alexander incorporated GIS technology with a standardized local climate zone (LCZ) classification framework to create the World Urban Database and Access Portal Tools (WUDAPT, http://www. wudapt.org) [33], which helped to standardize the definitions and characterizations of UCZs.

Studies of LCZs have generally been performed at large scales, e.g., at a city, provincial, or city cluster level [34-38]. In contrast, the spatiotemporal dynamics of street-level localities have rarely been studied. In this study, using the mono-window algorithm, high-resolution Landsat images from 2003, 2008, 2013, and 2019 were utilized in conjunction with contemporary building and meteorological data to determine the spatiotemporal variations in UHII for a number of LCZs. The findings of this study can serve as a scientific reference for urban planning researchers and guide efforts to improve the quality of urban residential environments.

\section{Study Area}

Zhongshan District is the financial and economic center of Dalian City, China. It is located in the eastern part $\left(38^{\circ} 51^{\prime}-38^{\circ} 55^{\prime} 30^{\prime \prime} \mathrm{N}, 121^{\circ} 37^{\prime} 30^{\prime \prime}-121^{\circ} 42^{\prime} 30^{\prime \prime} \mathrm{E}\right)$ of Dalian City, which includes 9 subdistricts (Figure 1) and has a total area of $43.85 \mathrm{~km}^{2}$ and a $27.5 \mathrm{~km}$-long coastline. Over the last decade, the Donggang subdistrict has undergone significant landscape changes as a result of land reclamation work, which has artificially altered the length and shape of its coastline. Such alterations are typical of Dalian City and other coastal cities. Hence, changes in the UHII of this region are likely representative of other coastal areas of China.

\section{Data Sources}

Dalian City is located in the northern warm temperate zone and has an oceanic, warm temperate monsoonal climate. From 2003 to 2019, hot days, during which the UHI effect is most significant, occurred most frequently in August. The average August temperature has increased by $2.3^{\circ} \mathrm{C}$ over the past 20 years, albeit with fluctuations. In 2003 and 2019, the average August temperatures were $23.6^{\circ} \mathrm{C}$ and $25.9^{\circ} \mathrm{C}$, respectively, reflecting intensified discomfort of urban environments in Dalian City. Therefore, we selected remote sensing images of Zhongshan in August to calculate its UHII.

Table 1 lists the remote sensing data, meteorological data, and building data used in this study, along with their sources. The remote sensing data are used for classifying the land use types, while the open source building data are employed for the detailed descriptions of building types. Building height and building density are indicative of building aggregation in the vertical and horizontal directions. To a certain extent, the two have the largest impacts on the urban form [39] and also correlate most strongly with the formation and development of UHIs [26]. Buildings were divided by height into three categories, per the 2019 Uniform standard for design of civil building (GB 50352-2019): lowrise residential buildings $(\leq 27 \mathrm{~m})$, high-rise residential buildings (27-100 $\mathrm{m})$, and super high rises $(>100 \mathrm{~m})$. Based on the findings of previous studies [40] and the current state of the study area, the buildings were also divided into lowdensity buildings $(\leq 40 \%)$ and high-density buildings $(>40 \%)$.

\section{Methods}

4.1. Local Climate Zones. The Landsat data were first geometrically calibrated and then masked and cropped. A polygon grid in the Albers projection of the study area was then generated using the Fishnet tool in the ArcGIS software (ESRI), and its intersections with the vector building data were tabulated. The land cover was then classified into four types (LCZs A-D) using visual interpretation and objectoriented classification, and the buildings were categorized as LCZs 1-6. The technical framework of this process is presented in Figure 2. Finally, the UHII of each LCZ was calculated from the LSTs inverted using the mono-window algorithm.

The procedure for dividing an area into LCZs is as follows. First, the climate of an area is divided into a number of smaller LCZs according to variations in the underlying surface. The LCZs that represent urban and rural climates are then selected and the UHII is determined by calculating the differences in temperature between these zones. The LCZ classification framework comprises 17 subclassifications of 


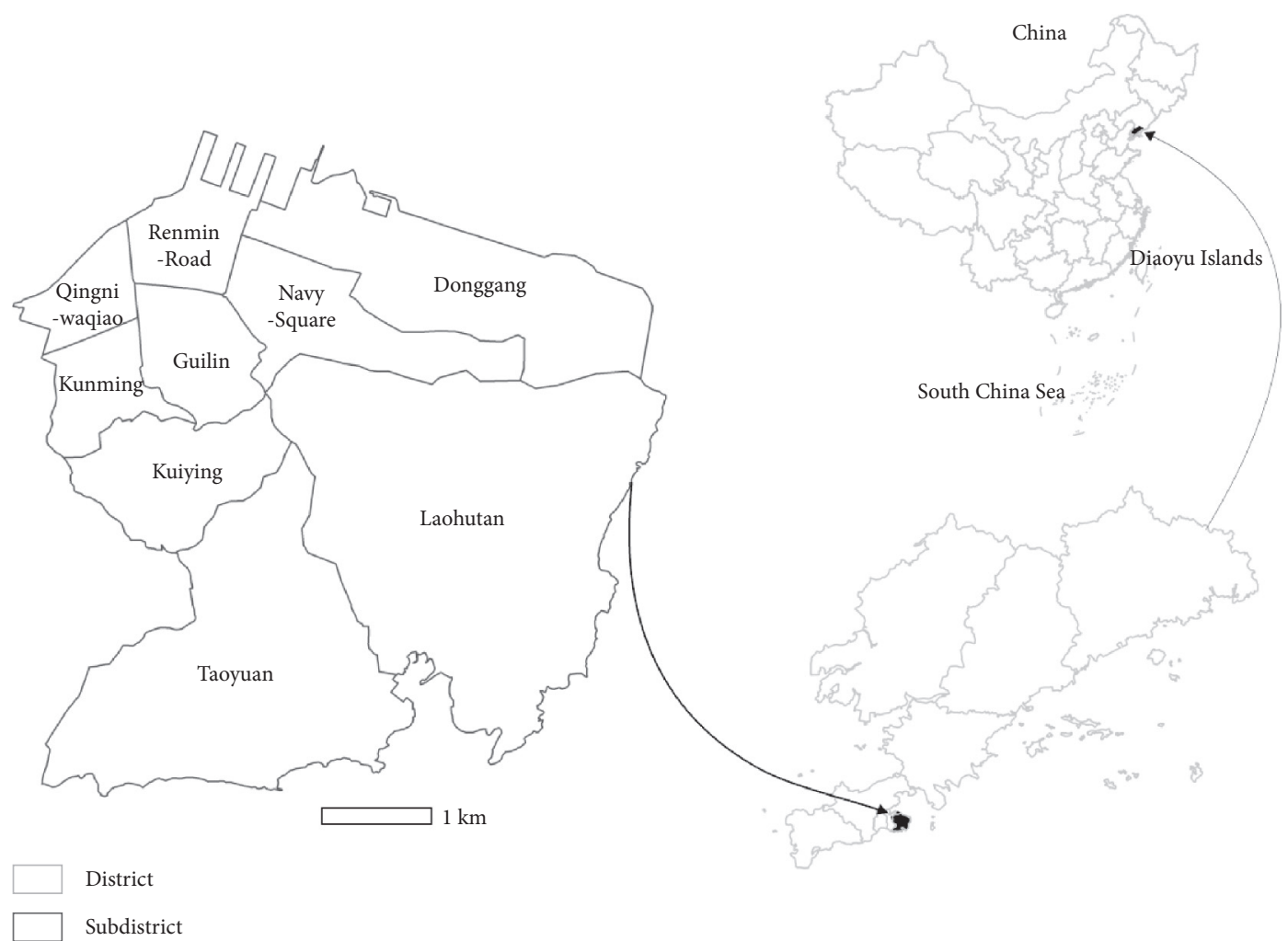

FIGURE 1: Location of the study area.

TABle 1: Datasets used in this study.

\begin{tabular}{|c|c|c|c|}
\hline Type & Time & Description & Source \\
\hline Remote sensing data & $\begin{array}{l}\text { August 28, } 2019 \\
\text { August 20, } 2013 \\
\\
\text { August 6, } 2008 \\
\text { August 25, } 2003\end{array}$ & $\begin{array}{c}\text { Landsat } 8 \text {-OLI } \\
\text { (30 m spatial resolution) } \\
\text { Landsat } 8 \text {-TIRS } \\
\text { (100 } \mathrm{m} \text { spatial resolution) } \\
\text { Landsat } 5 \text {-TM multispectral image } \\
\text { (30 m spatial resolution) } \\
\text { Infrared thermal imaging } \\
\text { (120 } \mathrm{m} \text { spatial resolution) }\end{array}$ & glovis.usgs.gov \\
\hline Building data & $\begin{array}{c}2003,2008 \\
2013,2019\end{array}$ & Building outline vector data & https://mobile.amap.com/ \\
\hline Meteorological data & $2003-2019$ & Monthly temperature data & data.cma.cn \\
\hline
\end{tabular}

buildings (LCZs 1-10) and land cover (LCZ A-G) [32]. In this manner, we enhanced the LCZ classification system to suit the needs of this study. High-resolution contemporary Google Earth images of the 10 subclasses were also used to validate the land cover types in the study area. A total of 1,000 samples were selected for this study, 600 of which were used for classification. The remaining samples were used to verify the accuracy. A high level of classification accuracy was achieved, with Kappa coefficients of 0.934, 0.952, 0.914, and 0.963 for the 2003, 2008, 2013, and 2019 data, respectively.

4.2. LST Inversion. LST is an important parameter for studying surface energy balance, as well as characterizing the
UHI effect. Methods for obtaining LSTs from inverted remote sensing data include the radiation transfer equation, mono-window algorithm, single-channel algorithm, and split-window algorithm. In an analysis of atmospheric water vapor contents estimated using the mono-window algorithm, Qin Zhi-hao and Rnieli [41, 42] found a significant negative correlation between atmospheric transmittance and LST estimation error. As Dalian City is located in the southernmost Liaodong Peninsula and experiences a hot and humid summer, its atmospheric transmittance is relatively low. Therefore, we selected the mono-window algorithm to retrieve the LSTs from the Landsat 5 TM6 and Landsat 8 TIRS 10 data. The equations for the mono-window algorithm are as follows (please note that all temperatures in this study are expressed in units of ${ }^{\circ} \mathrm{C}$ ): 


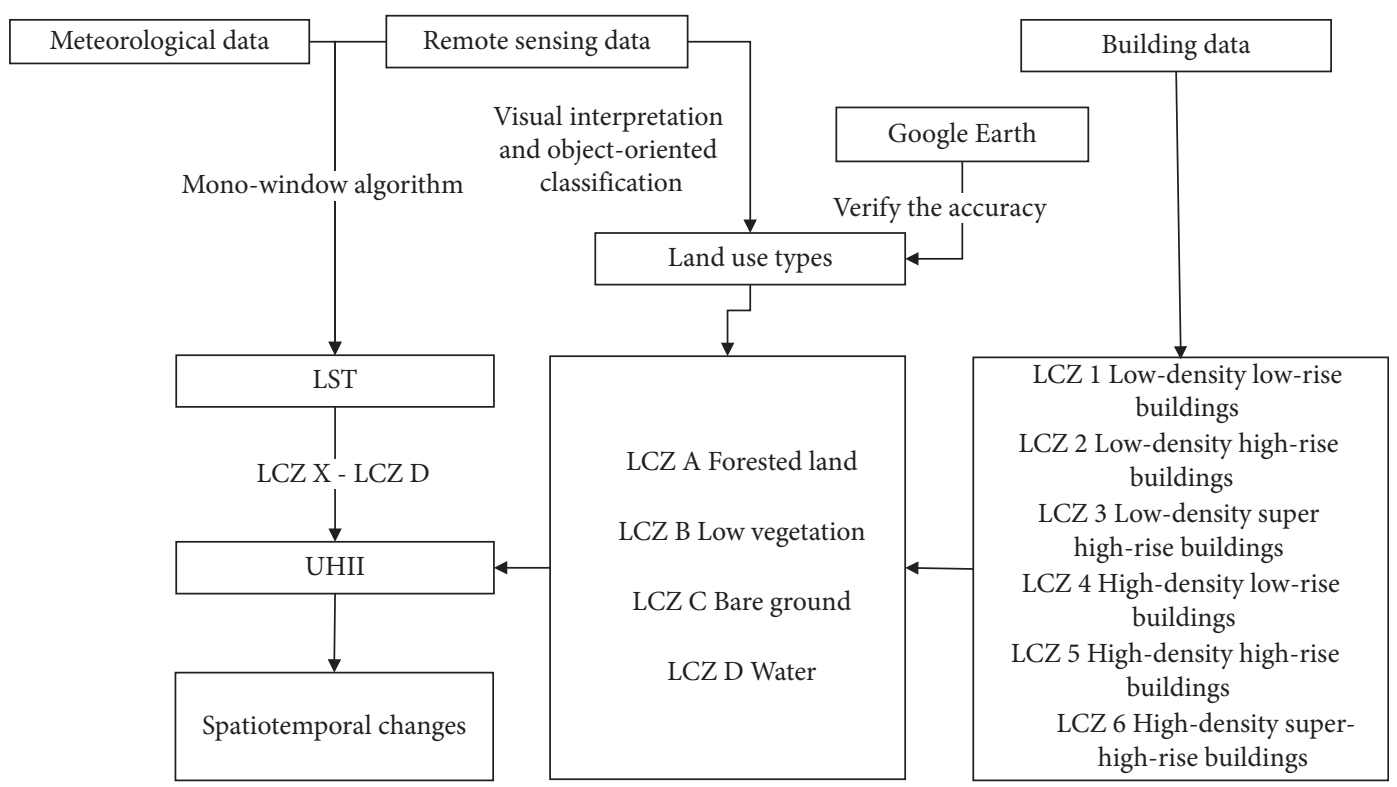

FIgURE 2: Technical framework of the method used in this study.

$$
\begin{aligned}
T_{s} & =\frac{\left(a(1-C-D)+T_{a}(b(1-C-D)+C+D)-D T_{6}\right)}{C}, \\
C & =\varepsilon \tau, \\
D & =(1-\varepsilon)[1+(1-\varepsilon) \tau],
\end{aligned}
$$

where $T_{s}$ is the inverted surface temperature $(K), a$ and $b$ are empirical constants $(a=-67.355351$ and $b=0.458606), T_{6}$ is the brightness temperature $(K)$, and $T_{a}$ is the effective mean atmospheric temperature $(K)$. $C$ and $D$ are intermediary variables, which are obtained from $\varepsilon$ (ground emissivity) and $\tau$ (the atmospheric transmittance of the TIR band).

4.3. Calculation of UHII. Based on our augmented LCZ system and the definition of UHII given by Stewart and Oke [31], we defined the UHII of each LCZ as the difference between its mean LST (estimated using the mono-window algorithm) and that of rural areas, as shown in the following:

$$
\mathrm{UHII}_{\mathrm{LCZ}}=\mathrm{LST}_{\mathrm{LCZX}}-\mathrm{LST}_{\mathrm{LCZB}} \text {, }
$$

where $\mathrm{LST}_{\mathrm{LCZ}} \mathrm{x}$ is the mean LST of all type-X LCZs and LST $_{\mathrm{LCZ}} \mathrm{B}$ is the mean LST of LCZ B (low and short vegetation).

\section{Results}

5.1. Local Climate Zones. With the implementation of policies such as the Chinese Economic Reform, the urbanization of Dalian City has progressed at an accelerated rate. The accompanying changes in each LCZ are listed in Table 2. From 2003 to $2019,0.759 \mathrm{~km}^{2}$ and $0.040 \mathrm{~km}^{2}$ of land were converted into LCZ A and LCZ D, respectively, but
$3.983 \mathrm{~km}^{2}$ and $0.435 \mathrm{~km}^{2}$ of these zones were converted into other land use types. Overall, the coverages of LCZs A and D decreased by $3.225 \mathrm{~km}^{2}$ and $0.395 \mathrm{~km}^{2}$, respectively. During the same period, $1.129 \mathrm{~km}^{2}, 1.319 \mathrm{~km}^{2}$, and $4.235 \mathrm{~km}^{2}$ of land were converted into LCZ B, LCZ C, and LCZ 1-6, respectively, while $0.196 \mathrm{~km}^{2}, 0.687 \mathrm{~km}^{2}$, and $2.179 \mathrm{~km}^{2}$ of their lands were converted into other land use types. Overall, the coverages of LCZs B, C, and 1-6 increased by $0.932 \mathrm{~km}^{2}$, $0.632 \mathrm{~km}^{2}$, and $2.056 \mathrm{~km}^{2}$, respectively. In Taoyuan, Laohutan, and Kuiying, large swaths of forested land were converted into construction land, roads, and areas with low vegetation cover. In Laohutan, Donggang, and Renmin Road, large amounts of riverine and marine areas were reclaimed and converted into residential areas, industrial and service areas, and roads.

From 2003 to 2019, the total area of construction land in Zhongshan increased substantially, and significant changes also occurred in terms of building heights and densities (Figure 3). The majority of low-density high-rises and super high-rises are located in the northern part of Guilin, the northeastern part of Navy Square, and along the border between Kuiying and Taoyuan, whereas high-density high rises and super high rises are mostly located in Qingniwaqiao and Renmin Road. Low-rise low-density and highdensity buildings are mainly located in Laohutan, Taoyuan, Navy Square, and Donggang. The building types in Laohutan and Taoyuan have changed significantly over time, with increases in the number of low-density high rises and super high rises. High-density low-rise buildings in Guilin have gradually been replaced by low-density low-rise buildings. High-density high-rise buildings have decreased in Navy Square and Renmin Road. In Kuiying, high-density low-rise buildings have decreased, while low-density high-rise zones have expanded. In Donggang, the number of buildings has increased over time due to land reclamation work and development; characteristic buildings in this subdistrict have changed gradually from low-density low rises to low-density 
TABLE 2: 2003-2019 land use type transfer summary.

\begin{tabular}{|c|c|c|c|c|c|c|c|}
\hline & \multirow{2}{*}{ Land use types } & \multicolumn{6}{|c|}{ Area in $2019\left(\mathrm{~km}^{2}\right)$} \\
\hline & & LCZ A & LCZ B & LCZ C & LCZ D & LCZ 1-LCZ 6 & Sum \\
\hline \multirow{6}{*}{ Area in $2003\left(\mathrm{~km}^{2}\right)$} & LCZ A & 15.769 & 0.543 & 0.35 & 0.001 & 3.094 & 19.752 \\
\hline & LCZ B & 0.014 & 0.106 & 0.002 & 0.000 & 0.181 & 0.302 \\
\hline & LCZ C & 0.079 & 0.048 & 0.212 & 0.000 & 0.560 & 0.898 \\
\hline & LCZ D & 0.006 & 0.029 & 0.000 & 0.154 & 0.400 & 0.589 \\
\hline & LCZ 1-LCZ 6 & 0.660 & 0.509 & 0.971 & 0.039 & 20.428 & 22.607 \\
\hline & Sum & 16.528 & 1.235 & 1.530 & 0.194 & 24.663 & - \\
\hline
\end{tabular}
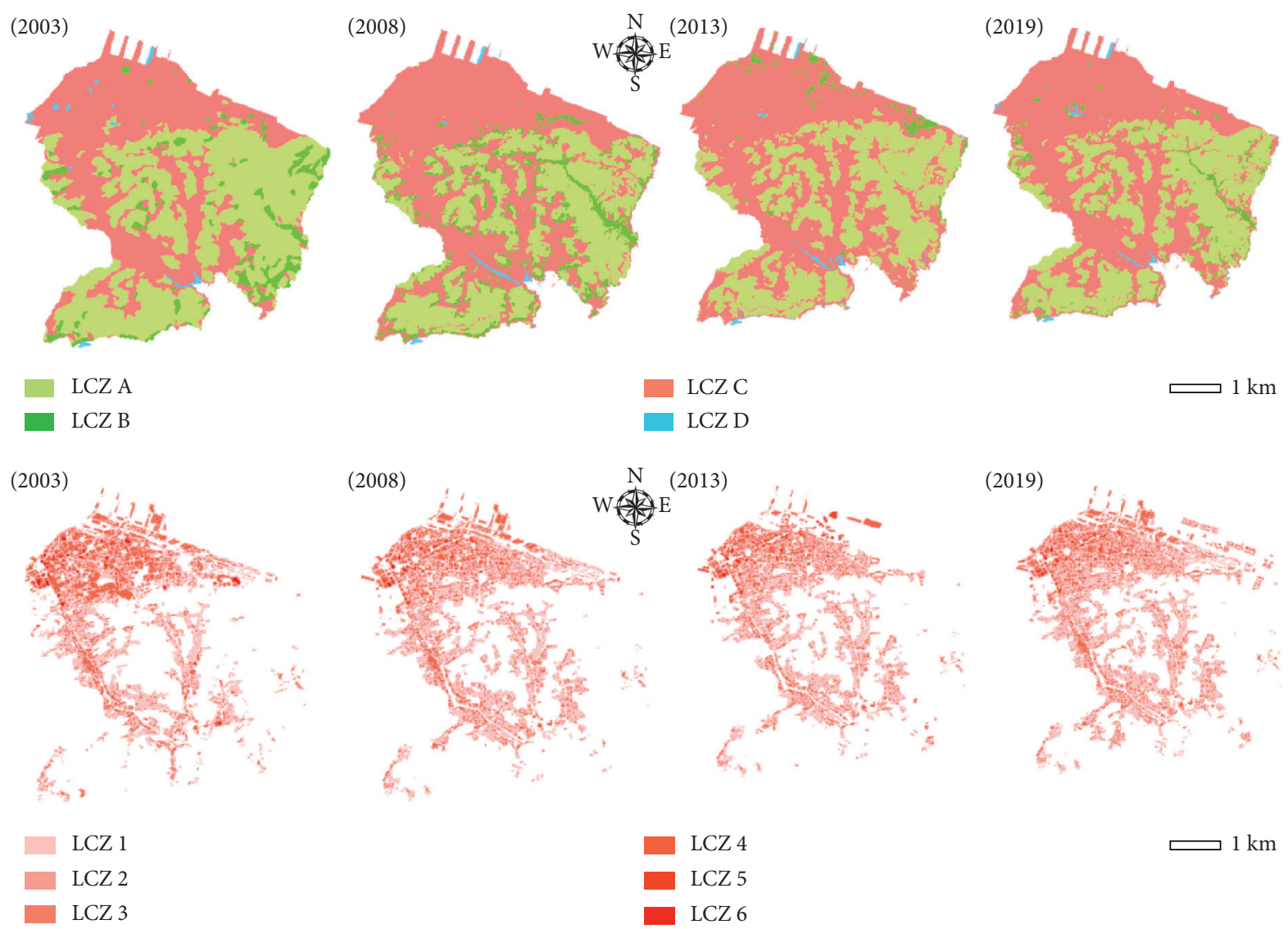

Figure 3: Classification results for different LCZs (2003-2019).

high rises, high-density low rises, and high-density super high rises.

5.2. Results of LST Inversion. The mono-window algorithm was used for LST inversion. The obtained data were validated against temperature data from ground-based weather stations and found to be highly accurate. The LST distribution in Zhongshan generally remained unchanged from 2003 to 2019 (Figure 4). High LST areas (red and orange-red zones) were mainly observed in the northwestern part of Zhongshan, which includes Renmin Road, Qingniwaqiao, Guilin, Kunming, and Navy Square, while low LST areas (blue and light blue zones) were mostly observed in Laohutan and Taoyuan. In 2003, the maximum LST in Zhongshan was $36.197^{\circ} \mathrm{C}$ (in the western part of Qingniwaqiao and at the border between Renmin Road and Donggang), and the minimum LST was $19.979^{\circ} \mathrm{C}$ (in the coastal areas of Taoyuan and Laohutan). The mean LST in Zhongshan in 2003 was $28.088^{\circ} \mathrm{C}$. In 2008 , the maximum LST was $33.382^{\circ} \mathrm{C}$ (mainly in Renmin Road, Qingniwaqiao, Guilin, Navy Square, and the center of Kuiying), and the minimum LST was $18.570^{\circ} \mathrm{C}$ (in the northern coastal areas of Donggang, southeastern coastal areas of Taoyuan, and coastal areas of Laohutan, which expanded due to land reclamation). The mean LST in Zhongshan in 2008 was $25.976^{\circ} \mathrm{C}$. The coverage of high LST areas increased in 2008, compared to that of 2003, indicating a higher UHII. This may be attributed to significant landform changes and the large-scale conversion of forested lands and water bodies into construction land. In 2013, the maximum and minimum LSTs were $34.325^{\circ} \mathrm{C}$ and $21.128^{\circ} \mathrm{C}$, respectively, and the mean LST was $27.726^{\circ} \mathrm{C}$. The 

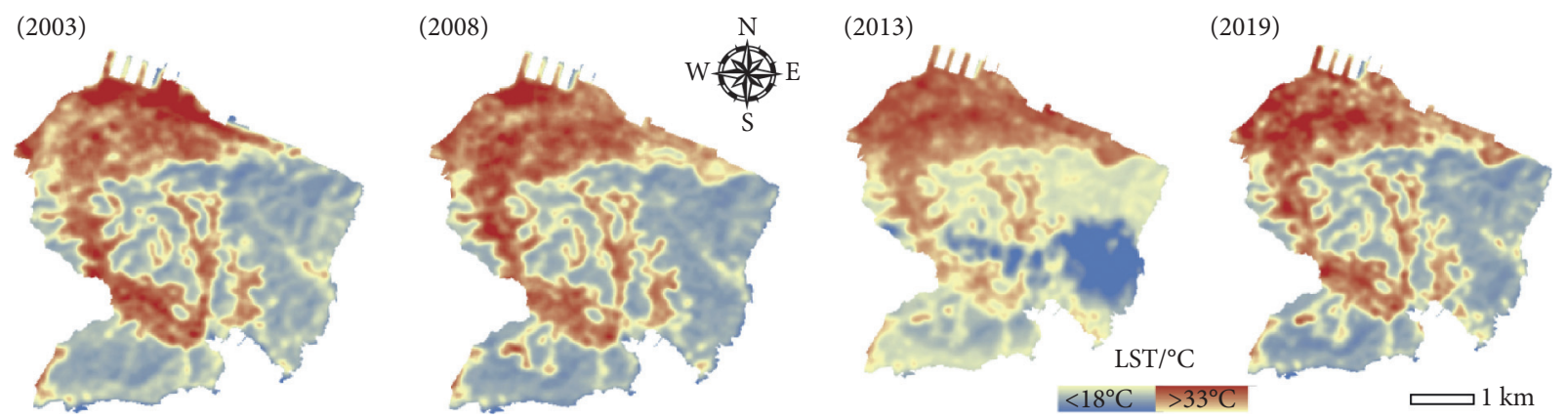

FIgURE 4: Distribution of land surface temperatures in Zhongshan (2003-2019).

subdistricts with the highest LSTs were the same as those in 2008, but the coverage of the maximum LST area in Qingniwaqiao and Renmin Road was significantly larger in 2013. The high LST areas in Kunming, Guilin, Navy Square, and Kuiying decreased to some extent, but the LSTs in Donggang increased in general. In 2019, the maximum, minimum, and mean LSTs in Zhongshan were $37.562^{\circ} \mathrm{C}$, $22.083^{\circ} \mathrm{C}$, and $29.823^{\circ} \mathrm{C}$, respectively, and the distribution of LSTs in 2019 remained largely unchanged from that of 2013.

Figures 3 and 4 show that high LSTs are spatiotemporally correlated with high-density buildings; high-density areas have a large number of buildings, forming a large impervious surface that increases the LST. With rapid urbanization, the building densities in Zhongshan have increased over time and the peak LSTs in this district have also increased accordingly.

5.3. Calculated UHII Values. From 2003 to 2019, all LCZs exhibited fluctuating growth patterns and significant increases in their average LSTs and UHIIs (Figure 5). The average LSTs of LCZs A-C increased by $1.610^{\circ} \mathrm{C}, 0.880^{\circ} \mathrm{C}$, and $3.830^{\circ} \mathrm{C}$, respectively, while the average LSTs of LCZs $1-6$ increased by $3.225^{\circ} \mathrm{C}, 3.226^{\circ} \mathrm{C}, 4.111^{\circ} \mathrm{C}, 2.639^{\circ} \mathrm{C}, 3.768^{\circ} \mathrm{C}$, and $4.052^{\circ} \mathrm{C}\left(\sim 2^{\circ} \mathrm{C}-4^{\circ} \mathrm{C}\right)$, respectively. As LCZ C mostly corresponds to bare, reclaimed lands near Donggang and the previously forested areas of Laohutan that were converted into residential and production land (which are mostly unused construction land as of 2019), it exhibits a particularly high average LST and UHII.

In 2003 , the average LSTs of LCZs A-C were $24.331^{\circ} \mathrm{C}$, $26.526^{\circ} \mathrm{C}$, and $27.187^{\circ} \mathrm{C}$, respectively, whereas those of LCZs $1-6$ ranged from $27^{\circ} \mathrm{C}$ to $29^{\circ} \mathrm{C}$. From 2003 to 2008 , the average LST of LCZ B changed significantly, decreasing by $2.403^{\circ} \mathrm{C}$; the LSTs of LCZs A and C also decreased by $1.450^{\circ} \mathrm{C}$ and $0.888^{\circ} \mathrm{C}$, respectively, and those of LCZs 1-6 ranged between $27^{\circ} \mathrm{C}$ and $28^{\circ} \mathrm{C}$. Among LCZs $1-6$, LCZ 4 had the largest decrease in average LST of $1.003^{\circ} \mathrm{C}$, whereas LCZ 6 had the smallest decrease of $0.061^{\circ} \mathrm{C}$. From 2008 to 2013, the average LST of LCZ C increased significantly by $2.437^{\circ} \mathrm{C}$; the average LSTs of LCZs A and B also increased by $1.988^{\circ} \mathrm{C}$ and $1.954^{\circ} \mathrm{C}$, respectively. The average LSTs of LCZs 1-6 in 2013 ranged between $28^{\circ} \mathrm{C}$ and $30^{\circ} \mathrm{C}$; the average LST of LCZ 6 increased by more than $2^{\circ} \mathrm{C}\left(2.225^{\circ} \mathrm{C}\right)$, while LCZ 2 had the smallest increase of $1.344^{\circ} \mathrm{C}$. The average LSTs of the other $\mathrm{LCZs}$ increased by $1.379^{\circ} \mathrm{C}-1.941^{\circ} \mathrm{C}$. From 2013 to 2019 , the average LST of LCZ C continued to increase significantly by $2.281^{\circ} \mathrm{C}$, and the average LSTs of LCZs A and B each increased by approximately $1^{\circ} \mathrm{C}\left(1.072^{\circ} \mathrm{C}\right.$ and $1.330^{\circ} \mathrm{C}$, respectively). The average LSTs of LCZs 1-6 ranged between $31^{\circ} \mathrm{C}$ and $32^{\circ} \mathrm{C}$, with LCZs 5 and 6 having the largest and smallest increases, respectively, in average LST $\left(2.612^{\circ} \mathrm{C}\right.$ and $1.889^{\circ} \mathrm{C}$, respectively). The average LSTs of the other LCZs increased by $2.206^{\circ} \mathrm{C}-2.517^{\circ} \mathrm{C}$.

In 2003, the UHIIs of LCZs A and C were -2.195 and 0.661 , respectively. The UHIIs of LCZs 1-6 ranged from 1.370 to 2.977 , following the order LCZ $4>$ LCZ $5>\mathrm{LCZ}$ $2>\operatorname{LCZ} 3>\operatorname{LCZ} 6>$ LCZ 1 . Although the LSTs of all the LCZs decreased in 2008, their UHIIs continued to increase significantly. The UHIIs of LCZs A and C were -1.241 and 2.177, respectively, and the UHIIs of LCZs 1-6 ranged from 3.337 to 4.535 , following the order LCZ $5>$ LCZ $4>$ LCZ 3 > LCZ $2>$ LCZ $6>$ LCZ 1. In 2013, although the LSTs of the LCZs increased significantly, their UHIIs did not increase. The UHIIs of LCZs A and C were -1.207 and 2.660, respectively, and the UHIIs of LCZs 1-6 ranged from 2.762 to 4.515 , following the order LCZ $6>$ LCZ $5>$ LCZ $3>$ LCZ $4>$ LCZ $2>$ LCZ 1. In 2019, all the LCZs reached their maximum LST and UHII values. The UHIIs of LCZs A and C were -1.465 and 3.611, respectively, and those of LCZs 1-6 ranged from 3.744 to 5.379 , following the order LCZ $5>$ LCZ $4>\operatorname{LCZ} 3>\operatorname{LCZ} 6>\operatorname{LCZ} 2>\operatorname{LCZ} 1$.

\section{Discussion}

6.1. Improvements to Model Accuracy. In terms of scale, previous studies of the UHI effect have mainly focused on large-scale spatial analyses at a provincial or city cluster level using low-resolution remote sensing images. In contrast, this study used high-resolution Landsat TIR data to study the spatiotemporal variations of UHI over a small region. In terms of methodology, most studies have used the urban landscape index and land-use types to explain changes in LST or UHI based on the two-dimensional (2D) layout of cities. For example, Fabeku et al. used satellite-derived index maps and explained that the significant increase in the LST of Ibadan was caused by the large-scale conversion of vegetated land into construction land [43]. Based on MODIS and Landsat remote sensing images, Wang et al. used models to extract NMDI, IBI, and NDBI indexes to explore their relationship with LST [44]. However, this approach overlooks 


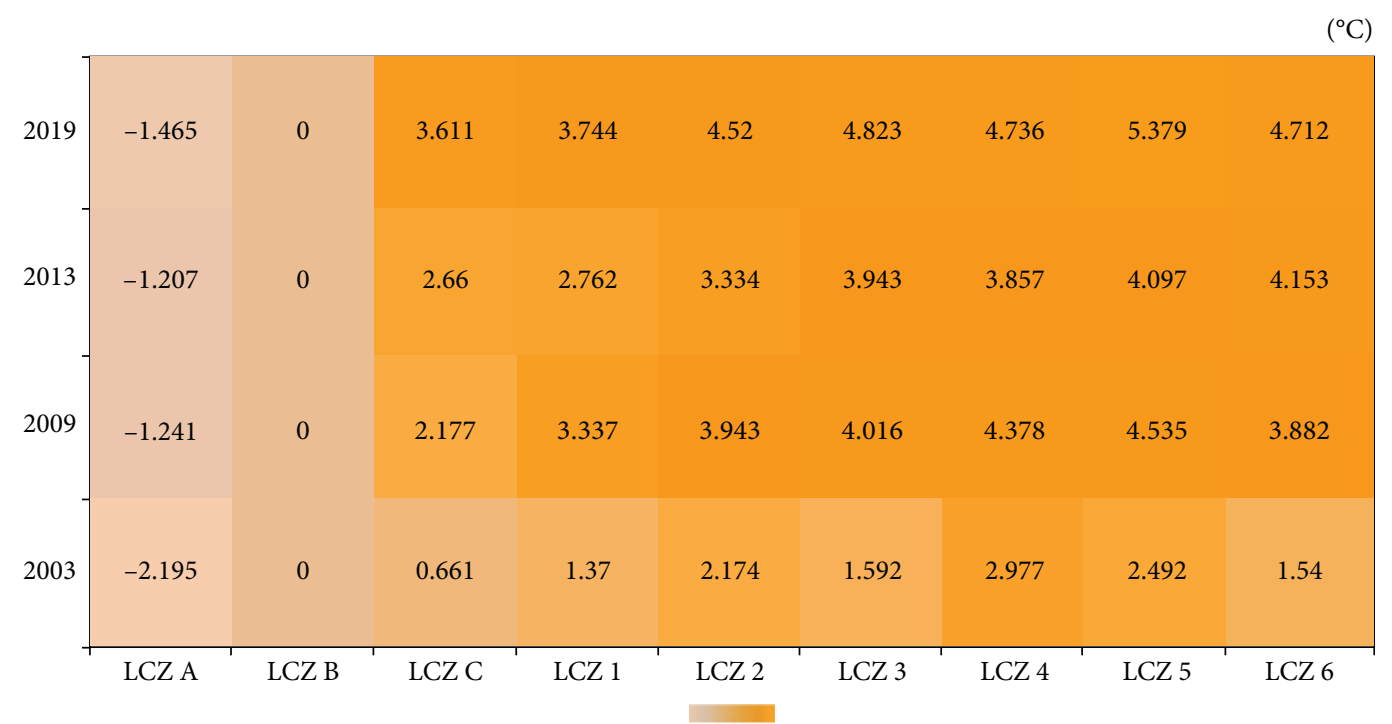

FIgURE 5: Average urban heat island intensities of the various LCZs (2003-2019).

the constraints imposed by three-dimensional (3D) buildings on urban morphology, which can influence urban heat environments $[45,46]$. In this study, we used an LCZ classification framework to account for 3D urban morphology attributes such as building height and building density. The LCZ classification framework was also modified according to the actual conditions in the study area and previous findings. By using a multiperspective method to compute the UHII of the study area, we effectively improved the practical implications and scientific rigor of our UHII calculations.

In summary, we conducted an empirical study of the UHI effect using the LCZ classification framework and fused 2D urban layouts with 3D morphological attributes to investigate spatiotemporal UHII variations from multiple perspectives. In addition, we analyzed spatiotemporal variations of LST and UHII in the study area over a comparatively long timescale. Whether and how the process of urbanization affects global climate change has consistently attracted significant attention over the last few decades. The results presented in this study clearly show how the 3D form of urban buildings (height and density) affect the quality of the urban thermal environment. It provides a scientific reference for government departments to aid in relevant decision-making in matters, such as urban planning and land use approval. Furthermore, the study enriches theoretical research on urban microclimate.

6.2. Limitations. This study had a few limiting factors and shortcomings. For example, the high-resolution Landsat TIR data used in this study are not sufficiently precise to provide detailed characteristics of the thermal-infrared features of the ground surfaces. Although the building data used in this study were calibrated in Google Earth Pro 2019, our data deviated slightly from real building data. Only building height and building density were used to represent building parameters, because they have the largest influences on urban morphologies and correspond most directly to the UHI effect. However, the effects of heat retention capacity and sky view factors on urban heat environments were not considered $[45,46]$. Furthermore, we focused on investigating the effects of building morphology and land use type on UHII because, along with artificial heat sources, they are currently believed to be the main determining factors of UHII. However, we did not consider other factors such as artificial heat sources and building materials [47-49], which might result in localized UHII estimation errors.

Although the above limitations will affect the accuracy of the findings to some extent, they do not affect the objectivity or scientific rigor of this study. To resolve these issues, we plan to use long and accurate time series data from multiple sources to further investigate spatiotemporal variations in the UHI effect.

\section{Conclusions}

In this study, remote sensing, meteorological, and building data were used to investigate the spatiotemporal dynamics of the UHII of the LCZs in the Zhongshan District of Dalian City. The findings of this study are as follows:

(1) Rapid urbanization has led to significant changes in urban land use and conversions of land types. From 2003 to 2019, the coverages of LCZs A and D decreased by $3.225 \mathrm{~km}^{2}$ and $0.395 \mathrm{~km}^{2}$, respectively, whereas the coverages of LCZs B, C, and 1-6 increased by $0.932 \mathrm{~km}^{2}, 0.632 \mathrm{~km}^{2}$, and $2.056 \mathrm{~km}^{2}$, respectively. The number of low-density high rises and super high rises increased in Laohutan and Taoyuan, and low-density low-rise buildings became increasingly dominant in Guilin. The number of buildings in Donggang also increased over time. On the whole, low-density high rises, high-density low 
rises, and high-density high rises have become more common in Zhongshan.

(2) High LST regions usually contain large aggregations of high-density buildings and appear to be spatiotemporally correlated. High LST areas (red and orange-red areas) are concentrated around Renmin Road, Qingniwaqiao, Guilin, Kunming, and Navy Square, whereas low LST areas (blue and dark blue zones) are mostly located around Laohutan and Taoyuan. Over the past 20 years, the maximum and minimum LSTs of Zhongshan have increased by $1.365^{\circ} \mathrm{C}$ and $1.104^{\circ} \mathrm{C}$, respectively.

(3) In 2019, all LCZs reached their maximum LST and UHII values. The average LSTs of LCZs A-C increased by $1.610^{\circ} \mathrm{C}, 0.880^{\circ} \mathrm{C}$, and $3.830^{\circ} \mathrm{C}$, respectively, and the average LSTs of LCZs 1-6 increased by approximately $2^{\circ} \mathrm{C}-4^{\circ} \mathrm{C}$. The UHIIs of LCZs A and C increased by 0.730 and 2.950 , respectively, and those of LCZs 1-6 increased from 1.370-2.977 to 3.744-5.379.

\section{Data Availability}

Data are available on request.

\section{Conflicts of Interest}

The authors declare that there are no conflicts of interest.

\section{Acknowledgments}

This research study was supported by the National Natural Science Foundation of China (Grant no. 41630749). The authors would like to thank all experts for their contributions to the urban thermal environment and urban planning.

\section{References}

[1] T. F. Stocker and G. K. Plattner, "Working group i contribution to the fifth assessment report of the intergovernmental panel on climate change," in Climate Change 2013: The Physical Science BasisIPCC, Geneva, Switzerland, 2013.

[2] Q. Wang, P. Shi, T. Lei et al., "The alleviating trend of drought in the huang-huai-hai plain of China based on the daily SPEI," International Journal of Climatology, vol. 35, no. 13, pp. 3760-3769, 2015.

[3] L. Zhou, J. Wu, X. Mo et al., "Quantitative and detailed spatiotemporal patterns of drought in China during 20012013," Science of the Total Environment, vol. 589, pp. 136-145, 2017.

[4] Q. Wang, J. Qi, H. Wu et al., "Freeze-Thaw cycle representation alters response of watershed hydrology to future climate change," Catena, vol. 195, Article ID 104767, 2020.

[5] J. Yang, Y. Wang, C. Xiu et al., "Optimizing local climate zones to mitigate urban heat island effect in human settlements," Journal of Cleaner Production, 2020, In press.

[6] A. I. Ciobotaru Ana-Maria, N. Dey, M. Petralli, R. M. Daneshvar Mohammad, and Q. Wang, "Temperaturehumidity index described by fractal higuchi dimension affects tourism activity in the urban environment of focşani city (romania)," Theoretical and Applied Climatology, vol. 136, no. 3-4, pp. 1009-1019, 2019.

[7] W. S. Feng Zhangxian and S. Jin, "Effects of urban morphology and wind conditions on land surface temperature in changchun," Acta Geographica Sinica, vol. 74, pp. 902-911, 2019.

[8] H. N. Qiao Zhi and X. XU, "Spatio-temporal pattern and evolution of the urban thermal landscape in metropolitan beijing between 2003 and 2017," Acta Geographica Sinica, vol. 74, pp. 475-489, 2019.

[9] A. Guo, J. Yang, W. Sun et al., "Impact of urban morphology and landscape characteristics on spatiotemporal heterogeneity of land surface temperature," Sustainable Cities and Society, vol. 63, Article ID 102443, 2020.

[10] J. Yang, X. S. Jin, J. C. XiaJin, and S. Wang, "Local climate zone ventilation and urban land surface temperatures: towards a performance-based and wind-sensitive planning proposal in megacities," Sustainable Cities and Society, vol. 47, Article ID 101487, 2019.

[11] J. Yang, J. Sun, Q. Ge, and X. Li, “Assessing the impacts of urbanization-associated green space on urban land surface temperature: a case study of dalian, China," Urban Forestry \& Urban Greening, vol. 22, pp. 1-10, 2017.

[12] P. Xie, J. Yang, H. Wang et al., "A new method of simulating urban ventilation corridors using circuit theory," Sustainable Cities and Society, vol. 59, Article ID 102162, 2020.

[13] Y. Jun, G. Yingying, X. Jianhong et al., "Spatiotemporal variation characteristics of green space ecosystem service value at urban fringes: a case study on ganjingzi district in dalian, China," Science of the Total Environment, vol. 639, pp. 1453-1461, 2018.

[14] B. Mashhoodi, D. Stead, and A. van Timmeren, "Spatializing household energy consumption in The Netherlands: socioeconomic, urban morphology, microclimate, land surface temperature and vegetation data," Data in Brief, vol. 29, Article ID 105118, 2020.

[15] P. Yang, G. Ren, and W. Hou, "Impact of daytime precipitation duration on urban heat island intensity over beijing city," Urban Climate, vol. 28, Article ID 100463, 2019.

[16] J. Yang, X. Luo, C. Jin et al., "Spatiotemporal patterns of vegetation phenology along the urban-rural gradient in coastal Dalian, China," Urban Forestry and Urban Greening, vol. 54, Article ID 126784, 2020.

[17] I. D. Stewart, "A systematic review and scientific critique of methodology in modern urban heat island literature," International Journal of Climatology, vol. 31, no. 2, pp. 200-217, 2011.

[18] C. He, L. Ma, L. Zhou et al., "Exploring the mechanisms of heat wave vulnerability at the urban scale based on the application of big data and artificial societies," Environment International, vol. 127, pp. 573-583, 2019.

[19] Y. Zeng, Z. Li, Q. Wang, C. Xu, Y. Li, and J. Tang, "Metal accumulation in asiatic clam from the lower min river (China) and implications for human health," Frontiers of Earth Science, vol. 13, no. 2, pp. 361-370, 2019.

[20] Q. Wang, J. Zeng, S. Leng et al., "The effects of air temperature and precipitation on the net primary productivity in China during the early 21 st century," Frontiers of Earth Science, vol. 12, no. 4, pp. 818-833, 2018.

[21] W. X. Feng Lei and X. He, "Fine forecast of high road temperature along jiangsu highways based on INCA system and METRo model," Journal of Applied Meteorological Science, vol. 28, pp. 109-118, 2017. 
[22] B. Candy, R. W. Saunders, D. Ghent, and C. E. Bulgin, "The impact of satellite-derived land surface temperatures on numerical weather prediction analyses and forecasts," Journal of Geophysical Research: Atmospheres, vol. 122, no. 18, pp. 9783-9802, 2017.

[23] X. Wang and C. Prigent, "Comparisons of diurnal variations of land surface temperatures from numerical weather prediction analyses, infrared satellite estimates and in situ measurements," Remote Sensing, vol. 12, no. 3, pp. 583-600, 2020.

[24] R. Fonseca, M. P. Zorzano-Mier, A. Azua-Bustos et al., "A surface temperature and moisture Intercomparison study of the weather research and forecasting model, in:itu measurements, and satellite observations over the atacama desert," Quarterly Journal of the Royal Meteorological Society, vol. 145, no. 722, pp. 2202-2220, 2019.

[25] D. G. Hooker Josh and C. Alessandro, "A global dataset of air temperature derived from satellite remote sensing and weather stations," Scientific Data, vol. 5, 2018.

[26] Z. L. Lin, "A study of urban heat island intensity based on "Local climate zones"” Journal of Geo-Information Science, vol. 19, pp. 713-722, 2017.

[27] J. Yang, A. Guo, Y. Li, Y. Zhang, and X. Li, "Simulation of landscape spatial layout evolution in rural-urban fringe areas: a case study of ganjingzi district," GIScience \& Remote Sensing, vol. 56, no. 3, pp. 388-405, 2018.

[28] D. Guilbert, K. S. Caluwaerts, and V. N. T. CnuddeVan Den Bossche, "Impact of the urban heat island on freeze-thaw risk of natural stone in the built environment, a case study in Ghent, Belgium," Science of The Total Environment, vol. 677, no. 10, pp. 9-18, 2019.

[29] M. F. De Kock, "Assessment of surface urban heat island intensity and its causes in the city of baghdad," IOP Conference Series: Materials Science and Engineering, vol. 745, Article ID 012162, 2020.

[30] I. D. Stewart, T. R. Oke, and E. S. Krayenhoff, "Evaluation of the "local climate zone" scheme using temperature observations and model simulations," International Journal of Climatology, vol. 34, no. 4, pp. 1062-1080, 2014.

[31] A. H. Auer, "Correlation of land use and cover with meteorological anomalies," Journal of Applied Meteorology, vol. 17, no. 5, pp. 636-643, 1978.

[32] I. D. Stewart and T. R. Oke, "Local climate zones for urban temperature studies," Bulletin of the American Meteorological Society, vol. 93, no. 12, pp. 1879-1900, 2012.

[33] C. Z. H. Guifeng, "Assessing land surface temperature in the mountain city with different urban spatial form based on local climate zone scheme," Mountain Research, vol. 36, pp. 617627, 2018.

[34] J. Chunhong Zhao and Q. Weng, “Application of airborne remote sensing data on mapping local climate zones: cases of three metropolitan areas of texas, U.S," Computers, Environment and Urban Systems, vol. 74, pp. 175-193, 2019.

[35] Y. Shi, Y. Xiang, and Y. Zhang, "Urban design factors influencing surface urban heat island in the high-density city of guangzhou based on the local climate zone," Sensors, vol. 19, no. 16, 3459 pages, 2019.

[36] B. Bechtel, D. Matthias, M. Gerald et al., "SUHI analysis using local climate zones-a comparison of 50 cities," Urban Climate, vol. 28, Article ID 100451, 2019.

[37] K. K Lau, S. C. Chung, and C. Ren, "Outdoor thermal comfort in different urban settings of sub-tropical high-density cities: an approach of adopting local climate zone (LCZ) classification," Building and Environment, vol. 154, pp. 227238, 2019.

[38] S. Liu and Q. Shi, "Local climate zone mapping as remote sensing scene classification using deep learning: a case study of metropolitan China," ISPRS Journal of Photogrammetry and Remote Sensing, vol. 164, pp. 229-242, 2020.

[39] G. A. Yang Jun and J. Xi, "Spatial-Temporal differentiation of three-dimensional urban landscape pattern: a case study of zhongshan district in dalian," Acta Geographica Sinica, vol. 72, pp. 646-656, 2017.

[40] K. K. W. Wan, C. L. Tsang, and J. C. Lam, "Sensitivity analysis of building energy use in different climates," IFAC Proceedings Volumes, vol. 43, no. 1, pp. 58-62, 2010.

[41] Z. M.-H. Qin Zhi-hao and A. N. K. Rnieli, "Mono-window algorithm for retrieving land surface temperature from Landsat TM6 data," Acta Geographica Sinica, vol. 56, pp. 456-466, 2001.

[42] Z. M. Shi Xin and Z. Liu, "Comparative analysis on three land surface temperature inversion algorithm based on Landsat8 data over sanheba basin," Remote Sensing Technology and Application, vol. 33, pp. 465-475, 2018.

[43] B. B. Fabeku, I. A. Balogun, S. A.-A. Adegboyega, and O. I. Faleyimu, "Spatio-Temporal variability in land surface temperature and its relationship with vegetation types over ibadan, South-Western Nigeria," Atmospheric and Climate Sciences, vol. 8, no. 3, pp. 318-336, 2018.

[44] J. W. Wang, W. T. L. Chow, and Y. C. Wang, "A global regression method for thermal sharpening of urban land surface temperatures from MODIS and Landsat," International Journal of Remote Sensing, vol. 41, no. 8, pp. 2986-3009, 2020.

[45] M. Srivanit and H. Kazunori, "The influence of urban morphology indicators on summer diurnal range of urban climate in Bangkok Metropolitan Area, Thailand," International Journal of Civil \& Environmental Engineering, vol. 11, no. 5, 2011.

[46] M. Scarano and F. Mancini, "Assessing the relationship between sky view factor and land surface temperature to the spatial resolution," International Journal of Remote Sensing, vol. 38, no. 23, pp. 6910-6929, 2017.

[47] J. A. Voogt and T. R. Oke, "Thermal remote sensing of urban climates," Remote Sensing of Environment, vol. 86, no. 3, pp. 370-384, 2003.

[48] A. Soux, J. A. Voogt, and T. R. Oke, "A model to calculate what a remote sensor "sees" of an urban surface," BoundaryLayer Meteorology, vol. 112, no. 2, pp. 401-424, 2004.

[49] X. Luo, Y. Zhang, and D. Sun, "Response patterns of vegetation phenology along urban-rural gradients in urban areas of different sizes," Complexity, vol. 2020, Article ID 7607936, 11 pages, 2020. 